PII S0957-4271(97)00028-1

Guest Editorial

\title{
The Third International Symposium on the Head/Neck System
}

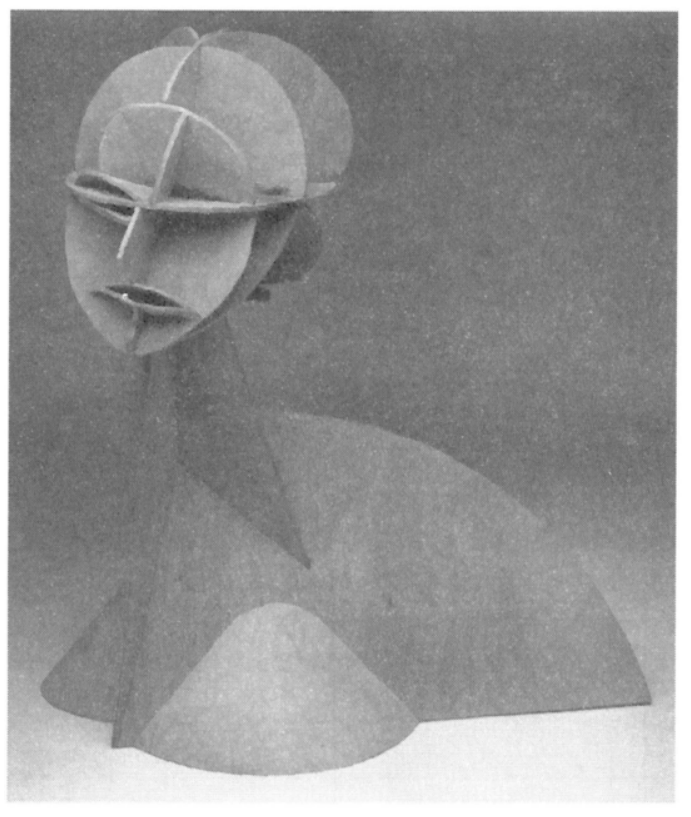

The collection of papers in this and the next issue of the Journal of Vestibular Research is a record of the Third International Symposium on the Head/Neck System held July 2-6, 1995 in Vail Colorado. The first meeting of the group, in Whistler, British Columbia in 1986, marked the first time head movements had been the central theme of an entire meeting, providing a defining moment that accelerated research and focused resources. The second meeting, at Fountainbleu, France in 1989, attracted scientists from outside the group traditionally concerned with eye-head coordination, and infused the community with new conceptual approaches to understanding head and neck movements. The organizers of the first two meetings-Barry Peterson, Frances Richmond, Alain Berthoz, Werner Graf, and Pierre Paul Vidal-approved of our wish to make two of the pioneers in our field the nucleus of the third meeting. We honored Geoffrey Melvill Jones and Horst Mittelstaedt with special sessions. The scientific program and all the participants attempted to emulate the special combination of scientific depth, breadth, and endurance characteristic of the contributions to our field by these two brilliant men. With this inspiration we hoped this symposium would continue and extend the objectives established previously: To understand more about the function of the head/ neck system itself and its pivotal role in orienting and many other behaviors.

The objective of any scientific meeting includes encouraging exchange of information and ideas, presentation of exciting and yet untested ideas, and assessment of previously published data in a new context. However, the Head/Neck Symposium participants agreed that the published record should include only new data or syntheses that were concurred upon and that could pass the normal peer review process, so the articles being published here and in volume 7 , number 4 do not represent everything that went on at the conference. For example, an evening debate about collicular mechanisms of eye-head coordination following one paper by Freedman and Sparks and another by Robinson and Cowie was spirited and informative, but it did not lead to a written presentation.

The papers from the meeting do not fit into one issue of the Journal of Vestibular Research. The current issue features twelve papers representing original research presented at the meeting. Two of these papers-one by Graf, Keshner, Richmond, Shinoda, Statler, and Uchino and another by Allum, Gresty, Keshner, and Schupert-summarize and synthesize the content of groups of papers contributed by many authors. The rest of the articles represent significant advances in all of the domains covered in 
the meeting: Cervical motor systems, biomechanics, control of head movements during postural corrections, perception of ego-motion and of the world, eye-head coordination, clinical and developmental insights, gaze stabilization, virtual reality, and the effects of space flight. Volume 7, number 4 will contain four review papers presented in a session devoted to Professor Horst Mittelstaedt, including one by the honoree. All four attempt to deal with the elaborate control mechanisms involved in multisensory and motor control of posture and movement and attest to the fundamental role still being played by the reafference principle which Mittelstaedt introduced with von Holst almost 50 years ago.

The reader must decide what advances this set of papers, including the one entitled "How to Construct and Move a Cat's Neck," represents over the artistic concepts illustrated in the photo of Noam Gabo's sculpture "Constructed
Head No.1," which was on the cover of the symposium program and is reproduced above.

Without Ken and Anna Taylor of Scientific Conference Planners, the meeting would not have succeeded. They arranged all the logistics with ultimate professionalism and sensitivity to the needs of science. Everything from the scrutiny of the program and the set-up of meeting rooms to the arrangement of social events fostered scientific exchange. The Westin Resort supported the meeting with wonderful accommodations and a spread of desserts that attracted unprecedented numbers to the poster sessions, even after the weather cleared up. We thank the Journal of Vestibular Research for providing a forum to present our proceedings.

P. DiZio

J. R. Lackner

T. Mergner 